Check for updates

Cite this: RSC Adv., 2017, 7, 41163

Received 6th April 2017

Accepted 15th July 2017

DOI: $10.1039 / c 7 r a 03898 d$

rsc.li/rsc-advances

\section{Effects of Rhizoma Parisdis total saponins and its main compounds on gastric emptying via regulating muscarinic receptors in vitro and in vivo}

\author{
Yu Wang, (D) $\dagger^{\text {acd }}$ Yuanxue Liu, (D) $\dagger^{a}$ Genbei Wang, (D) $\dagger^{\text {acd }}$ Liying Han, (D) ${ }^{a}$ Ting Xia, (D) a
} Zhen Liu, ${ }^{\mathrm{b}}$ Shuli Man, (DD ${ }^{\mathrm{b}}$ Wenyuan Gao (iD) *a and Changxiao Liu ${ }^{\mathrm{e}}$

The aim of this study was to explore the inhibitory effect of Rhizoma Parisdis total Saponins (RPS) and the main monomer compounds (polyphyllin I, II, VI and H) on gastric emptying and gastrointestinal motility in vitro and in vivo. The in vivo experiments demonstrated that mosapride $\left(2.25 \mathrm{mg} \mathrm{kg}^{-1}\right)$ and neostigmine $\left(0.1 \mathrm{mg} \mathrm{kg}^{-1}\right.$ ) could promote gastric emptying, while RPS (250 and $500 \mathrm{mg} \mathrm{kg}^{-1}$ ), adrenalin $(0.3 \mathrm{mg}$ $\left.\mathrm{kg}^{-1}\right)$, atropine $\left(2 \mathrm{mg} \mathrm{kg}^{-1}\right)$ and dopamine $\left(1 \mathrm{mg} \mathrm{kg}^{-1}\right)$ inhibited gastric emptying. Neostigmine markedly enhanced the delayed gastric motility induced by RPS in mice. The delaying effect of RPS was abolished by atropine and dopamine treatments but not adrenalin. RPS reduced gastric emptying by several pathways, which involved regulating muscarinic receptors. From the in vitro experiments we found that RPS and the main monomer compounds (polyphyllin I, II, VI and H) (20-160 $\mu \mathrm{g} \mathrm{ml}^{-1}$ ) concentrationdependently inhibited the contractions in the antral circular strip compared to untreated controls. Besides, RPS and polyphyllin I, II, VI and $\mathrm{H}$ partly prohibited the stimulatory effect of acetylcholine $(10 \mu \mathrm{M})$ but RPS-induced relaxation was significantly reduced by pretreatment with atropine (10 $\mu \mathrm{M})$ on gastric antral smooth muscle contractility (GASMC). In addition, we also found that polyphyllin I and II had a stronger inhibitory effect on GASMC than that of polyphyllin $\mathrm{VI}$ and $\mathrm{H}$. The experiment indicated that RPS could inhibit the gastric emptying, with polyphyllin I, II, VI and $\mathrm{H}$ being the major active ingredients. Meanwhile, the inhibition of gastric emptying and contractions of the antral circular strip by RPS predominantly involves muscarinic receptors.

\section{Introduction}

Among the traditional systems of medicine, traditional Chinese medicine (TCM) is the most extraordinary one with unique theory and thousands of years of practice in promoting people's health and alleviating diseases. As treatments for diseases, herbal medicines have advantages in reducing side effects, promoting the immune system, and prolonging survival time of people with cancer. In recent years, steroidal saponins isolated

${ }^{a}$ Tianjin Key Laboratory for Modern Drug Delivery \& High-Efficiency, School of Pharmaceutical Science and Technology, Tianjin University, Weijin Road, Tianjin 300072, China. E-mail: biochemgao@163.com; Fax: +86-22-8740-1895; Tel: +86-228740-1895

${ }^{b}$ College of Biotechnology, Tianjin University of Science \& Technology, Tianjin 300193, China

${ }^{c}$ Tasly Academy, Tasly Holding Group Co., Ltd., No. 2 Pujihe East Road, Tasly TCM Garden, Beichen District, Tianjin 300410, China

${ }^{d}$ State Key Laboratory of Core Technology in Innovative Chinese Medicine, Tasly Holding Group Co., Ltd., No. 2 Pujihe East Road, Tasly TCM Garden, Beichen Distric, Tianjin 300410, China

${ }^{e}$ The State Key Laboratories of Pharmacodynamics and Pharmacokinetics, Tianjin, 300193, China

$\dagger$ These three authors contributed equally to this work. from herbs have attracted scientific attention because of their structural diversity and significant biological activities. Rhizoma Paridis total Saponins (RPS) as the active parts of P. polyphylla Smith var. yunnanensis has been used as antitumor ${ }^{1}$ and hemostatic agents ${ }^{2}$ in China for a long time. In previous work, RPS was identified as the main effective components of Rhizoma Paridis. ${ }^{3-7}$ We investigated the in vitro antitumor effect and the safety evaluation of RPS, and found that it showed good cytotoxicity and adverse effects on the gastric area. ${ }^{\mathbf{8}-11}$ However, the effects of RPS on gastrointestinal function have not been reported in detail.

According to the research on the pharmacological activities of $P$. polyphylla Smith var. yunnanensis, saponins in $P$. polyphylla Smith var. yunnanensis are both active constituents and toxic constituents. In fact, there are reports showing that ginseng saponins, which are isolated from the ginseng root, have effects on reducing acetylcholine. ${ }^{12}$ Acetylcholine $(\mathrm{ACH})$, an important neurotransmitter on regulating the gastrointestinal motility, ${ }^{13}$ can be combined with the acetylcholine receptors on gastrointestinal smooth muscle cells, then promote gut mobility via the stimulation of fast excitatory synaptic transmission. ${ }^{14}$ In most parts of the gastrointestinal tract, acetylcholine $(\mathrm{ACH})$ is the important neurotransmitter which initiate 
excitatory events in response to mechanical or chemical stimuli. ${ }^{\mathbf{1 5 , 1 6}}$ Cholinergic antagonism is a conventional approach to produce antispasmodic effects for inhibiting gastric emptying.

Our previous work has demonstrated that RPS inhibited gastric emptying in vivo ${ }^{\mathbf{1 7}}$ while it is unknown which constituents or pure compounds serve as stimulators or as inhibitors in the RPS. The aim of this study is to examine the activity of RPS and the main monomer compounds (polyphyllin I, II, VI and $\mathrm{H}$ ) on gastric emptying and gastrointestinal motility in vitro and in vivo. Gastric emptying is closely associated with smooth muscle contraction, and antral smooth muscle layer in the stomach is the thickest which may perform a key role in gastric emptying. Thus we investigate the effect of RPS on isolated antral smooth muscle motility. Furthermore, some antagonists and agonists, such as acetylcholine, adrenalin hydrochloride, atropine, dopamine, mosapride citrate and neostigmine, are used to identify the possible pathways of RPS-induced inhibitory effect on gastric emptying. Study on these issues not only offers better guidance for the clinical application of RPS but also provides foundation for new drug discovery.

\section{Materials and methods}

\section{Drugs and solution}

RPS was prepared by the previously reported method. ${ }^{3}$ Other drugs used in this study were acetylcholine, adrenalin hydrochloride (Kunming Pharmaceutical Group Co., Ltd., China), atropine, dopamine, mosapride citrate (Lunanbeite Pharmaceutical co., Ltd., China) and neostigmine (Qilu Pharmaceutical co., Ltd., China). Polyphyllin I (PubChem CID: 44429646), polyphyllin II (PubChem CID: 72960700), polyphyllin VI (PubChem CID: 71307571) and polyphyllin H (PubChem CID: 101615586) were purchased from Chinese food and Drug Inspection Institute. For oral administration, RPS was suspended in distilled water. For intraperitoneal (ip) injection, acetylcholine, adrenalin hydrochloride and so on, were dissolved in physiological saline. The Krebs solution used in this study contained (in millimolar): $\mathrm{NaCl}, 119 ; \mathrm{KCl}, 4.7 ; \mathrm{CaCl}_{2}, 2.5 ; \mathrm{MgSO}_{4} \cdot 7 \mathrm{H}_{2} \mathrm{O}, 1.2$; $\mathrm{NaHCO}_{3}, 25 ; \mathrm{NaH}_{2} \mathrm{PO}_{4}, 1.2$; glucose, $11, \mathrm{pH}=7.4$. The Krebs solution was bubbled continuously with a mixture of $95 \% \mathrm{O}_{2} /$ $5 \% \mathrm{CO}_{2}$ ( $\left.\mathrm{vol} / \mathrm{vol}\right)$.

\section{Animals}

Kunming mice (weighing 18 to $22 \mathrm{~g}$ for females) and wistar rats (weighing 180 to $220 \mathrm{~g}$ for female) were purchased from the Institute of Tianjin Laboratory Animal Center, Tianjin. Mice were kept at $25 \pm 1{ }^{\circ} \mathrm{C}$ under a 12 hours light/dark cycle condition, while freely access to food (standard pellet diet) and water ad libitum. All experimental protocols were approved by the Animal Ethics Committees of the Faculty of Medicine, Tianjin University, Tianjin, China, and carried out in accordance with "Principles of Laboratory Animal Care and Use in Research” (State Council of China, 1988).

\section{Analysis of the RPS by HPLC-ELSD}

The method used in this experiment was same to the previous reported. ${ }^{18}$ The chemical composition of RPS were analyzed by HPLC (Agilent 1100, USA) equipped with a Kromasil RP-C18 column $(4.6 \times 250 \mathrm{~mm}, 5 \mu \mathrm{m}$, Kromasil C18). The analytical column temperature was kept at $35{ }^{\circ} \mathrm{C}$. Acetonitrile (A) and water (B) under gradient conditions $(0-5 \mathrm{~min}, 33-36 \% \mathrm{~A} ; 5-$ 12 min, 36-45\% A; 12-18 min, 45-50\% A; 18-42 min, 50-43\% A; 42-45 $\min , 43-55 \% \mathrm{~A} ; 45-70 \mathrm{~min}, 55-100 \% \mathrm{~A})$ was the mobile phase at a flow rate of $1 \mathrm{ml} \mathrm{min}{ }^{-1}$. The injection volume was 20 $\mu \mathrm{L}$. The drift tube temperature for ELSD was set at $110^{\circ} \mathrm{C}$, and the nebulizing gas flow rate was $2.9 \mathrm{~L} \mathrm{~min}^{-1}$.

\section{Measurement of gastric emptying and small intestinal transit}

After $16 \mathrm{~h}$ of food deprivation, RPS (250 or $500 \mathrm{mg} \mathrm{kg}^{-1}$ ), mosapride citrate $\left(2.25 \mathrm{mg} \mathrm{kg}^{-1}\right)$, or distilled water was administered orally to Kunming mice. Adrenalin hydrochloride (0.3 $\mathrm{mg} \mathrm{kg}{ }^{-1}$, subcutaneous injection, sc), atropine ( $2 \mathrm{mg} \mathrm{kg}^{-1}$, intraperitoneal injection, ip), dopamine $\left(1 \mathrm{mg} \mathrm{kg}^{-1}\right.$, intraperitoneal injection, ip), or neostigmine $\left(0.1 \mathrm{mg} \mathrm{kg}^{-1}\right.$, intraperitoneal injection, ip) was injected $40 \mathrm{~min}$ later, and phenol red meal $(1.5 \%, 0.3 \mathrm{ml})$ was administered orally $5 \mathrm{~min}$ after the dopamine (ip) injection, 15 min after the adrenalin, atropine, neostigmine, or $20 \mathrm{~min}$ after mosapride citrate. All the animals were euthanized by cervical dislocation immediately $20 \mathrm{~min}$ after phenol red. Total stomach was removed after cardiac and pylorus ligated. The stomach was cut into pieces and homogenized with its contents in $25 \mathrm{ml}$ of $0.1 \mathrm{~N} \mathrm{NaOH}$. The homogenate was allowed to settle for $1 \mathrm{~h}$ at room temperature, and $8 \mathrm{ml}$ of the supernatant was added to $1 \mathrm{ml}$ of $33 \%$ of trichloroacetic acid to precipitate proteins. After centrifugation (3000 rpm for $30 \mathrm{~min}$ at $4{ }^{\circ} \mathrm{C}$ ), $2 \mathrm{ml}$ of $2 \mathrm{~N} \mathrm{NaOH}$ were added to the supernatant and the amount of phenol red was determined from the absorbency at $560 \mathrm{~nm}$. This correlates with the concentration of phenol red in the stomach, which in turn depends on the gastric emptying. The gastric emptying rate was derived as GE $=(1-X / Y) \times 100 . X$ is the absorbance of phenol red recovered from the stomach of animals killed 20 min after test meal. $Y$ is the mean absorbance of phenol red recovered from the stomachs of animals killed at $0 \mathrm{~min}$ following test meal.

Immediately after the excision of the stomach, the whole small intestine of mice was grossly freed from its mesenteric attachments. The small intestine was divided into 5 segments averagely. Every segment was treatment with the same method to stomach. The geometric center ${ }^{19}$ of the phenol red was used to represent small intestinal transit and calculated as follows:

$$
\text { Geometric center }=\sum\left(A_{n} n\right) / 100, n=1,2,3,4,5
$$

where, $A_{n}$ was the absorption of phenol red in the $n$th segment and $n$ was the number of the segment.

\section{Tissues preparation}

All male wistar rats were fasted overnight and sacrificed by cervical dislocation. The abdomen of each rat was opened 
along the midline and the stomach was removed in a preoxygenated Krebs solution. We cut the long axis of the stomach parallel to the circular muscle fibers and strips of the circular muscle layer $(2-10 \mathrm{~mm})$ were prepared. Then the stomach muscle strips were suspended in longitudinal direction in a chamber containing $10 \mathrm{ml}$ Krebs solution $\left(37^{\circ} \mathrm{C}\right)$ and bubbled with $95 \% \mathrm{O}_{2}$ and $5 \% \mathrm{CO}_{2}$. A computerized integration system (BIOPAC MP150; BIOPAC system, Inc., USA) was used to measure the spontaneously contractile activity of gastric antral circular strip.

\section{Effect of RPS on gastric antral smooth muscle contractility (GASMC)}

The contractile responses of the strips to RPS were measured according to the previously described method..$^{20}$ Briefly, an initial tension of $0.5 \mathrm{~g}$ for circular muscles was applied before treating with drugs. All tissues were incubated for 1 hour until a stable baseline was attained and then the experiment started. Four different concentrations of RPS (20, 40, 80 and 160 $\mu \mathrm{g} \mathrm{ml}^{-1}$ ) were administrated consecutively into the bath to note the responses of strips. The mean tension was measured for each concentration in the same way. For the further study, an appropriate agent (acetylcholine) at the final concentration of $10 \mu \mathrm{M}$ was pre-incubated with strips for $5 \mathrm{~min}$ and the responses of strips were recorded, followed by consecutive administration of concentrations of RPS as stated in the previous part. The basal levels (before using the drugs) served as control, so the values of drug-induced contractile responses were represented as a percentage of the control, means \pm S.E.M. of six experiments. To avoid interactions between agents, new strips were prepared for each experiment.

\section{Effect of polyphyllin I, II, VI and H on GASMC}

To determine the dominating activity component of RPS on gastric antral smooth muscle, four different concentrations of polyphyllin I, II, VI and $\mathrm{H}\left(20,40,80\right.$ and $\left.160 \mu \mathrm{g} \mathrm{ml}^{-1}\right)$ were administrated consecutively into the bath to note the responses of strips, respectively. Furthermore, the appropriate agent (acetylcholine), at the final concentration of 10 $\mu \mathrm{M}$ was pre-incubated with strips for $5 \mathrm{~min}$ and the responses of strips were recorded, followed by consecutive administration of concentrations of polyphyllin I, II, VI and $\mathrm{H}$ respectively as stated in the previous part. The method was similar to that of experiment we described above.

\section{Effect of acetylcholine on RPS-induced relaxation of isolated gastric antral smooth muscle}

The gastric antral smooth muscle was processed as described above. After an equilibration period of 1 hour, isolated gastric antral smooth muscle was incubated with RPS or the main compounds $\left(160 \mu \mathrm{g} \mathrm{ml} \mathrm{m}^{-1}\right)$ for $5 \mathrm{~min}$. Then, cumulativeconcentration response curves for acetylcholine (a muscarinic receptor agonist, $10^{-9}-10^{-4} \mathrm{M}$ ) were obtained. The nonincubation with muscarinic receptor agonist was considered as control group.

\section{Effect of atropine on RPS-induced relaxation of isolated gastric antral smooth muscle}

To assess whether RPS and the main compounds produced relaxation of isolated gastric antral smooth muscle through the inhibition of muscarinic receptors, isolated gastric antral smooth muscle was incubated with atropine (a muscarinic receptor antagonist, $10 \mu \mathrm{M}$ ) for $5 \mathrm{~min}$, followed by consecutive administration of concentrations of RPS or the main compounds as stated in the previous part. The non-incubation with muscarinic receptor antagonist was considered as control group.

\section{Statistical analysis}

Data were expressed as means \pm standard error (S.E.M.) or percentage and analyzed for statistical significance using one-way analysis of variance (ANOVA) followed by Student's $t$ test. Tests were performed using SPSS 17.0 system. $P$-Value less than or equal to 0.05 was considered to be statistically significant.

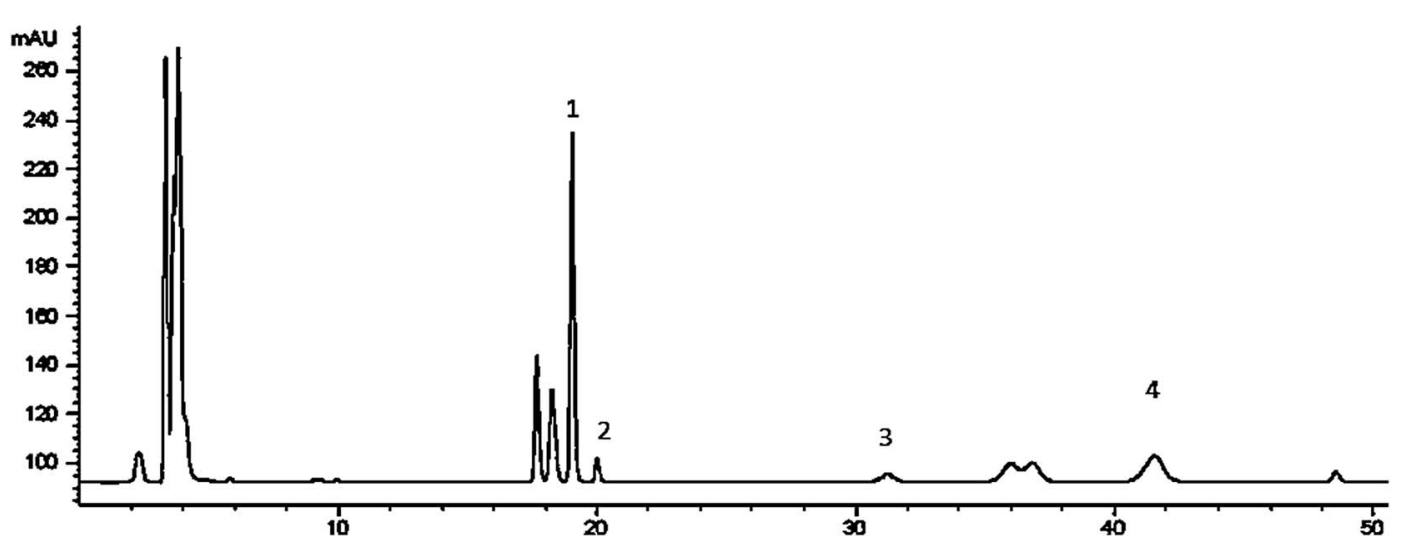

Fig. 1 HPLC-ELSD chromatograms of RPS ((1) polyphyllin H, (2) polyphyllin VI, (3) polyphyllin II, (4) polyphyllin I). 


\section{Results}

\section{Chemical composition analysis}

The chemical composition of RPS was qualitatively identified utilizing HPLC-ELSD by retention time with standard mixture solution. Fig. 1 shows the HPLC chromatograms of RPS. The contents of polyphyllin I ( $t_{\mathrm{R}} 41.823 \mathrm{~min}$, Fig. 1-2), polyphyllin II $\left(t_{\mathrm{R}} 31.110\right.$ min, Fig. 1-2), polyphyllin VI $\left(t_{\mathrm{R}} 19.674 \mathrm{~min}\right.$, Fig. 1-2), polyphyllin $\mathrm{H}\left(t_{\mathrm{R}} 18.964 \mathrm{~min}\right.$, Fig. 1-2) were $24.18 \pm 1.40 \mathrm{mg} \mathrm{g}^{-1}$,
$6.46 \pm 0.16 \mathrm{mg} \mathrm{g}^{-1}, 2.70 \pm 0.12 \mathrm{mg} \mathrm{g}^{-1}$ and $24.91 \pm 0.67 \mathrm{mg} \mathrm{g}^{-1}$ respectively.

\section{Gastric emptying and small intestinal motility of RPS}

In normal mice, gastric emptying was remarkable inhibited by RPS (250 or $500 \mathrm{mg} \mathrm{kg}^{-1}$, Fig. 3-5). Mosapride and neostigmine significantly promoted the gastric emptying, while RPS, adrenalin, atropine and dopamine evoked a significant decrease of gastric emptying (Fig. 3 and 4). The gastric

A

B

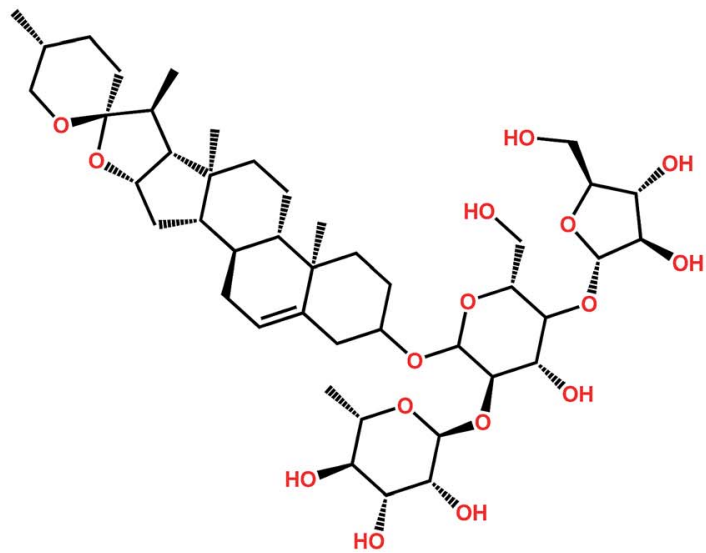

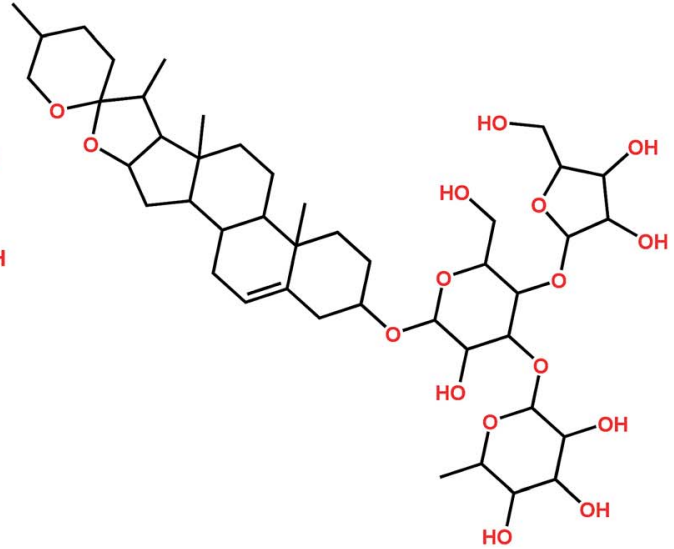

C

D

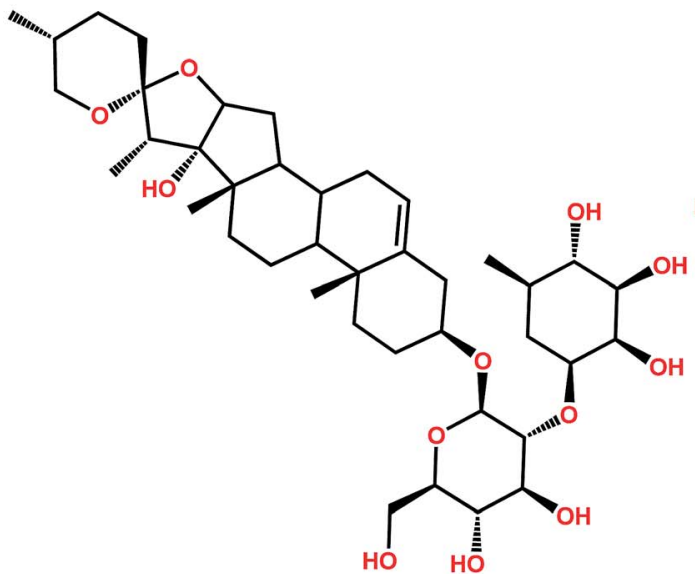

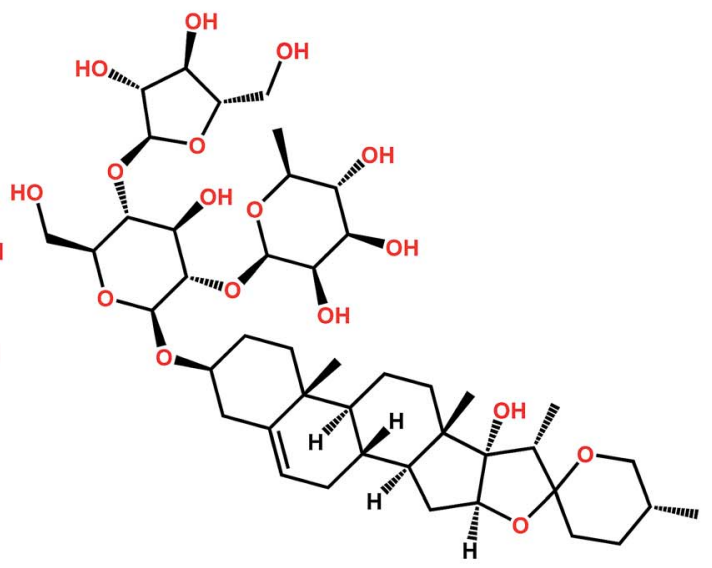

$\mathbf{E}$

$\mathbf{F}$

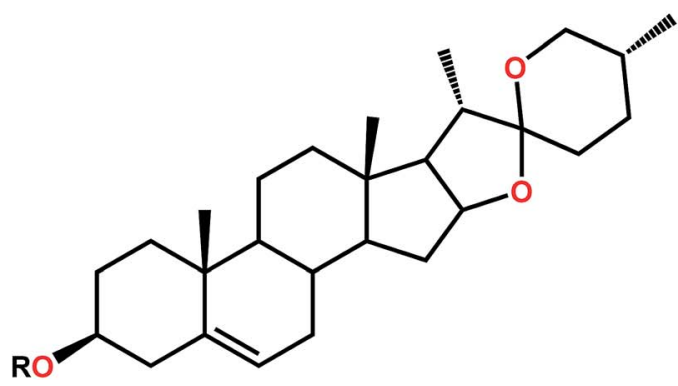

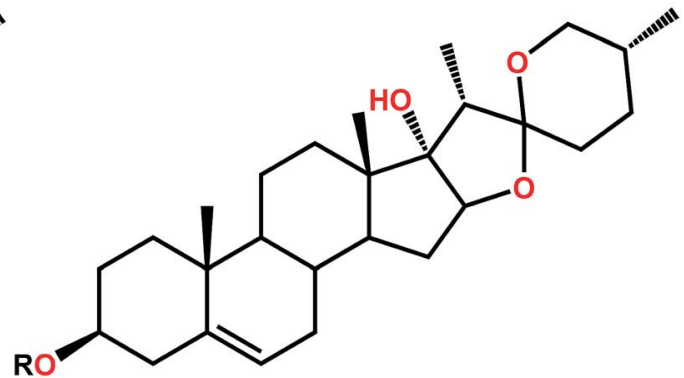

Fig. 2 Chemical structure of polyphyllin I (A), polyphyllin II (B), polyphyllin VI (C), polyphyllin H (D), diosgenins (E) and pennogenins (F). 


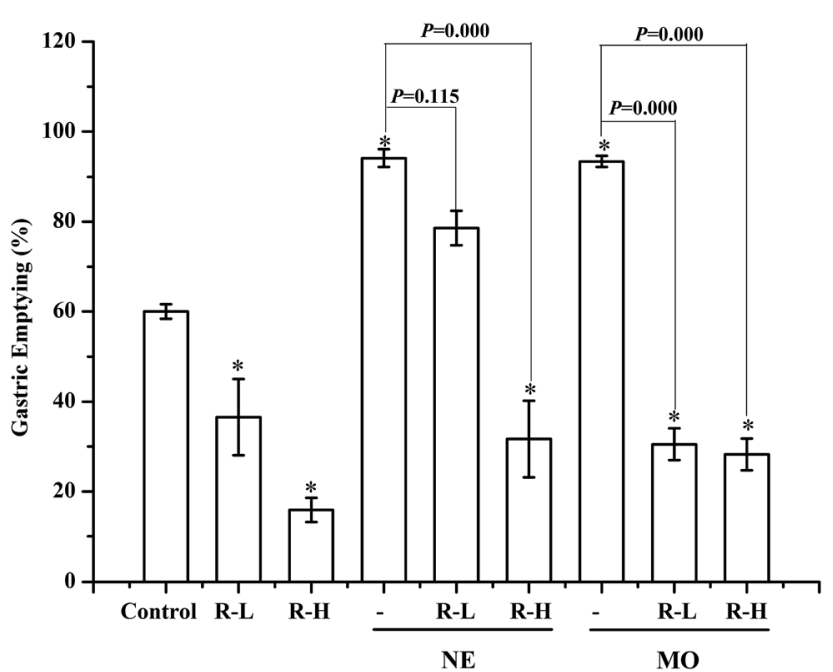

Fig. 3 The effects of neostigmine $\left(0.1 \mathrm{mg} \mathrm{kg}^{-1}\right)$ and mosapride (2.25 mg kg $\mathrm{g}^{-1}$ ) on gastric emptying in the absence or presence of 250 and $500 \mathrm{mg} \mathrm{kg}^{-1}$ RPS. Bars represent mean \pm S.E.M. $(n=10) . * P<0.05$ with respect to control.

emptying improved by neostigmine and mosapride was significantly abolished by administration with RPS $(500 \mathrm{mg}$ $\mathrm{kg}^{-1}, P=0.000$ ). The present results shows that adrenalin inhibited the gastric emptying and the inhibitory effect was significantly enhanced after pre-treatment with RPS (Fig. 4, $P=$ $0.016, P=0.000$ ), but the inhibitory effect is similar to RPS alone. Administration of RPS with pretreatment by atropine or dopamine had significantly effect on gastric emptying with dose dependent, but the inhibition rates were weaker than RPS alone (Fig. 4A).

Under basal conditions, geometric center of control group was $3.36 \pm 0.10$. RPS showed no effect on the geometric center compared with control group $(P>0.05)$. Mosapride and neostigmine gave little effect on the intestinal transit (Fig. 5A). The intestinal transit under adrenalin, atropine and dopamine treatment in the absence or the presence of RPS were shown in Fig. 5B. The intestinal transit was reduced by adrenalin alone, while increased with RPS. Atropine without or with RPS significantly attenuated intestinal transit and dopamine showed similar trend to adrenalin (Fig. 5B).

\section{Effects of RPS on GASMC}

Since the antral smooth muscle layer plays an important role in gastric emptying, we have investigated the effect of RPS on isolated antral smooth muscle motility. In order to investigate the effect of RPS on the spontaneous contractility of rat antral smooth muscle, RPS was administered at increasing concentrations $\left(20,40,80\right.$ and $\left.160 \mu \mathrm{g} \mathrm{ml}^{-1}\right)$ respectively. The basal levels (before using the drugs) served as control and the mean amplitude was tested for each concentration in the same way.

Here we found that RPS $\left(20-160 \mu \mathrm{g} \mathrm{ml} \mathrm{m}^{-1}\right)$ concentrationdependently reduced the mean tension of contractions in the antral circular strip compared to untreated controls $(n=6)$ (Fig. 6). The percentage of changing from control values were
$-14.00 \pm 1.61 \%\left(20 \mu \mathrm{g} \mathrm{ml}^{-1}\right),-18.70 \pm 0.71 \%\left(40 \mu \mathrm{g} \mathrm{m}{ }^{-1}\right)$, $-26.05 \pm 0.86 \%\left(80 \mu \mathrm{g} \mathrm{m}{ }^{-1}\right)$ and $-39.14 \pm 0.25 \%(160 \mu \mathrm{g}$ $\mathrm{ml}^{-1}$ ), respectively. The results indicated that the RPS had the effect of inhibiting smooth contractions. Significant differences between different concentrations of RPS with control were observed (Fig. 6).

Fig. 7 and Table 1 showed the effect of pretreatment with acetylcholine $(\mathrm{ACH})$ on the response of antral smooth muscle layer in RPS $\left(20-160 \mu \mathrm{g} \mathrm{ml}^{-1}\right)$. The maximum contraction elicited by ACH was $5.07 \pm 0.02 \mathrm{~g}$, which was attenuated to $4.42 \pm$ $0.05 \mathrm{~g}$ (RPS $\left.20 \mu \mathrm{g} \mathrm{ml}^{-1}, P<0.001\right), 4.00 \pm 0.02 \mathrm{~g}$ (RPS $40 \mu \mathrm{g} \mathrm{ml}^{-1}$, $P<0.001), 2.70 \pm 0.03 \mathrm{~g}$ (RPS $80 \mu \mathrm{g} \mathrm{ml}{ }^{-1}, P<0.001$ ) and $2.06 \pm$ $0.02 \mathrm{~g}(59.34 \%$ reduction, $P<0.001)$ at cumulative concentrations without washing between the administrations. As the Fig. 7B showed, the percentages of control values were $279.11 \pm$ $1.74 \%$ (ACH $10 \mu \mathrm{M}$ ), $230.66 \pm 3.62 \%$ (ACH $10 \mu \mathrm{M}+\mathrm{RPS} 20 \mu \mathrm{g}$ $\left.\mathrm{ml}^{-1}\right), 199.77 \pm 1.67 \%\left(\mathrm{ACH} 10 \mu \mathrm{M}+\mathrm{RPS} 40 \mu \mathrm{g} \mathrm{m}{ }^{-1}\right), 102.30 \pm$ $2.00 \%\left(\mathrm{ACH} 10 \mu \mathrm{M}+\mathrm{RPS} 80 \mu \mathrm{g} \mathrm{ml}{ }^{-1}\right.$ ) and $54.14 \pm 1.55 \%(\mathrm{ACH}$ $\left.10 \mu \mathrm{M}+160 \mu \mathrm{g} \mathrm{ml}{ }^{-1}\right)$. It was indicated that RPS $(20-160 \mu \mathrm{g}$ $\mathrm{ml}^{-1}$ ) had effect on smooth muscle contraction after treatment with acetylcholine $(10 \mu \mathrm{M})$.

\section{Effects of polyphyllin I, II, VI and H on GASMC}

In order to investigate the major active component of RPS on GASMC, polyphyllin I (Fig. 2A) and II (Fig. 2B) with polyphyllin VI (Fig. 2C) and $\mathrm{H}$ (Fig. 2D) which are the representative of diosgenins (Fig. 2E) and pennogenins (Fig. 2F) in RPS respectively, were performed in GASMC. Based on the above results, we compared the effects of the 4 individual components (polyphyllin I, II, VI and H) with RPS in the in vitro model. Polyphyllin I, II, VI and $\mathrm{H}\left(20,40,80\right.$ and $\left.160 \mu \mathrm{g} \mathrm{ml}^{-1}\right)$ were administrated into the bath to note the responses of strips, respectively. As shown in Fig. 8, polyphyllin I and II $\left(20-160 \mu \mathrm{g} \mathrm{ml} \mathrm{ml}^{-1}\right)$ concentration-dependently reduced the mean tension of contractions in the antral circular strip compared to untreated controls $(n=6)$. The percentage of changing from control values were from $-22.00 \pm 1.57 \%$ to $-58.21 \pm 0.22 \%$ (polyphyllin I) and from $-18.51 \pm 0.97 \%$ to $-41.63 \pm 0.48 \%$ (polyphyllin II), respectively. However, polyphyllin VI $\left(20-160 \mu \mathrm{g} \mathrm{ml}^{-1}\right)$ or polyphyllin $\mathrm{H}\left(20-160 \mu \mathrm{g} \mathrm{ml}^{-1}\right)$ used alone only had slighter effect on smooth muscle contraction. When compared to the control, the percentage of polyphyllin VI was $-28.32 \pm 0.87 \%(160 \mu \mathrm{g}$ $\left.\mathrm{ml}^{-1}\right)$ and of polyphyllin $\mathrm{H}$ was $-27.46 \pm 0.38 \%\left(160 \mu \mathrm{g} \mathrm{ml}^{-1}\right)$. Apparently, the effect of polyphyllin I and II $\left(20-160 \mu \mathrm{g} \mathrm{ml}^{-1}\right)$ on GASMC is stronger than that of polyphyllin VI and $\mathrm{H}(20-160 \mu \mathrm{g}$ $\mathrm{ml}^{-1}$ ) when used alone. The inhibitory effect of RPS on GASMC is also more significant than polyphyllin VI or $\mathrm{H}$ but weaker than polyphyllin I or II. Therefore, we may suspect that polyphyllin I and II which are saponins with diosgenin have a stronger inhibitory effect on GASMC than saponins with pennogenins.

On the basis of above results, acetylcholine $(10 \mu \mathrm{M})$, was used as a positive control to track down the possible sites of diosgenins and pennogenins' activity on gastric antral smooth muscle contractility. As shown in Fig. 9, pretreatment of gastric antral smooth muscle strips with acetylcholine $(10 \mu \mathrm{M})$ for 
A

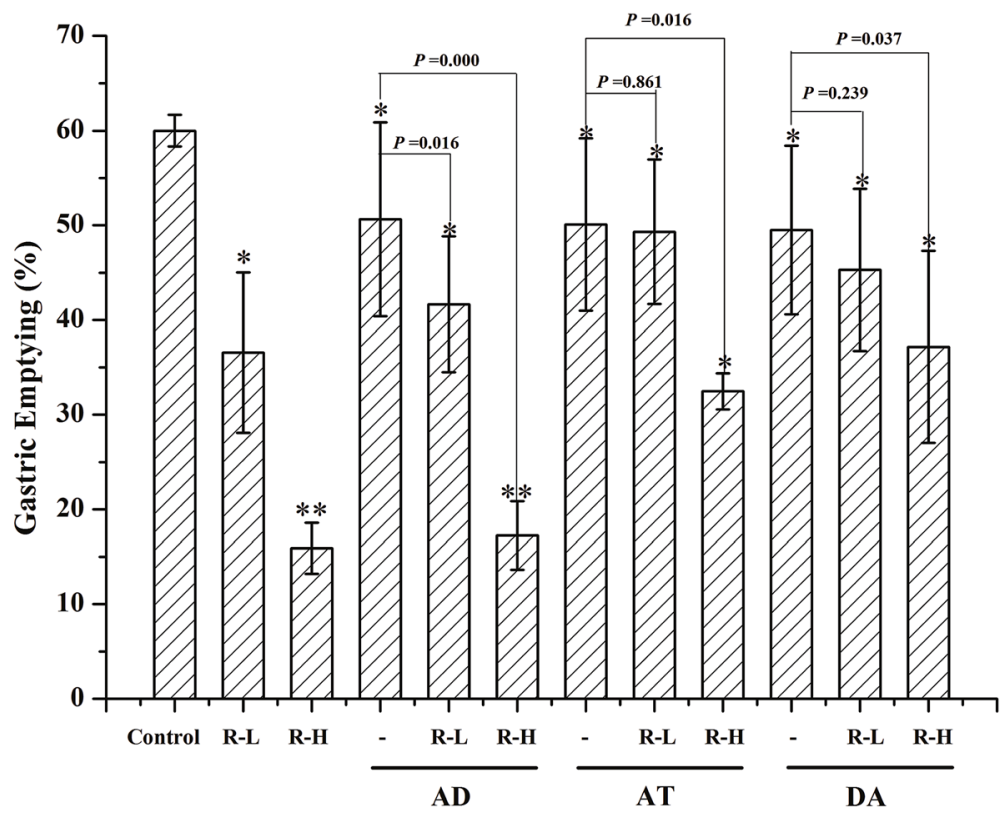

B

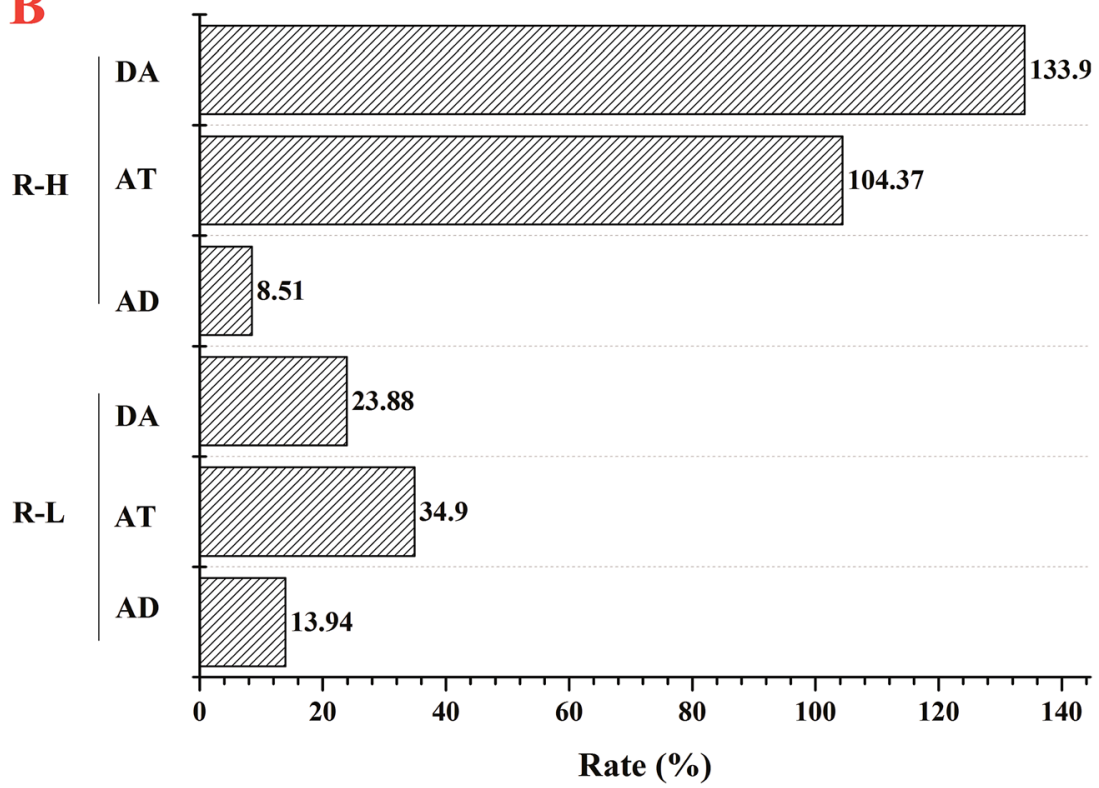

Fig. 4 The effects of adrenalin $\left(0.3 \mathrm{mg} \mathrm{kg}^{-1}\right)$, atropine $\left(2 \mathrm{mg} \mathrm{kg}^{-1}\right)$ and dopamine $\left(1 \mathrm{mg} \mathrm{kg}^{-1}\right)$ on gastric emptying in the absence or presence of 250 and $500 \mathrm{mg} \mathrm{kg}^{-1} \mathrm{RPS}$ (A). (B) Represent the increased rate of adrenalin, atropine and dopamine under the treatment of RPS when compared RPS alone. Bars represent mean \pm S.E.M. $(n=10)$. $* P<0.05$ with respect to control.

5 min was partly abolished by polyphyllin I, II, VI and $\mathrm{H}$ (20-160 $\mu \mathrm{g} \mathrm{m} \mathrm{m}^{-1}$ ) induced relaxation in smooth muscle strip contraction. The percentage of changing from control values after administrated by RPS were from $269.11 \pm 1.74 \%$ to $54.14 \pm$ $1.55 \%$ (214.97\% reduction, $P<0.001$, Fig. 9A). As shown in Fig. 9B, compared to the control, the maximum sustained percentage elicited by acetylcholine $(10 \mu \mathrm{M})$ was $264.38 \pm 8.13 \%$ which was attenuated to $42.70 \pm 7.68 \%$ (221.68\% reduction, $P<$ 0.001 ) in the presence of $160 \mu \mathrm{g} \mathrm{ml} \mathrm{m}^{-1}$ polyphyllin I. The maximum sustained percentage elicited by acetylcholine
$(10 \mu \mathrm{M})$ was $268.54 \pm 9.39 \%$ which was attenuated to $49.56 \pm$ $3.11 \%$ (218.98\% reduction, $P<0.001$, Fig. 9C) in the concentration of $160 \mu \mathrm{g} \mathrm{ml}^{-1}$ polyphyllin II. The maximum contraction induced by acetylcholine $(10 \mu \mathrm{M})$ was $268.76 \pm 8.77 \%$, which was attenuated to $94.63 \pm 4.60 \%$ (174.13\% reduction, $P<0.001$, Fig. 9D) in the presence of polyphyllin VI. The maximum contraction induced by acetylcholine $(10 \mu \mathrm{M})$ was $268.22 \pm 5.61 \%$, which was attenuated to $83.02 \pm 3.48 \%$ (185.20\% reduction, $P<0.001$, Fig. 9E) in the presence of polyphyllin $\mathrm{H}$. 

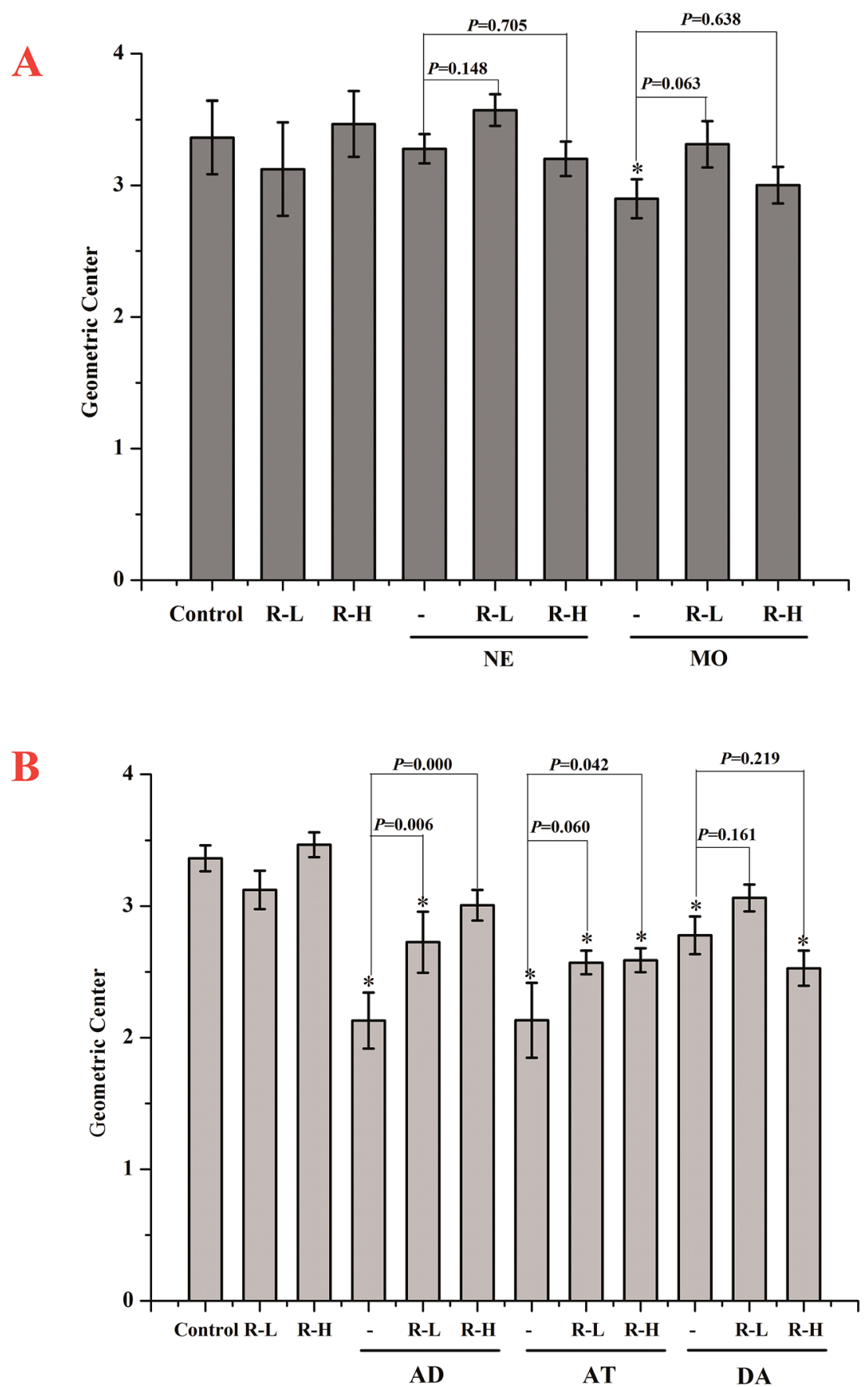

Fig. 5 The effects of neostigmine and mosapride (A), adrenalin, atropine and dopamine (B) on intestinal motility in the absence or presence of 250 and $500 \mathrm{mg} \mathrm{kg}^{-1}$ RPS. Bars represent mean \pm S.E.M. $(n=10) . * P<0.05$ with respect to control.

The order of reduced percentage of changing from acetylcholine $(10 \mu \mathrm{M})$ in GASMC was the following: polyphyllin I > polyphyllin II $>$ RPS $>$ polyphyllin VI $>$ polyphyllin $\mathrm{H}$. The inhibitory effect of polyphyllin I and II on antral smooth muscle constriction was stronger than that of polyphyllin VI and $\mathrm{H}$. The present study has indicated that diosgenins showed significantly inhibitory activity compared to pennogenins with pretreatment of antral smooth muscle strips with acetylcholine $(10 \mu \mathrm{M})$.

\section{Effect of acetylcholine on RPS-induced relaxation of isolated} gastric antral smooth muscle

After incubated with RPS, polyphyllin I, polyphyllin II, polyphyllin VI or polyphyllin $\mathrm{H}\left(160 \mu \mathrm{g} \mathrm{ml}^{-1}\right)$ for $5 \mathrm{~min}$, cumulative-concentration response curves for acetylcholine $\left(10^{-9}-10^{-4} \mathrm{M}\right)$ were obtained. As shown in Fig. 10, the cumulative concentration-response curves for acetylcholine applied to the isolated gastric antral smooth muscle were 


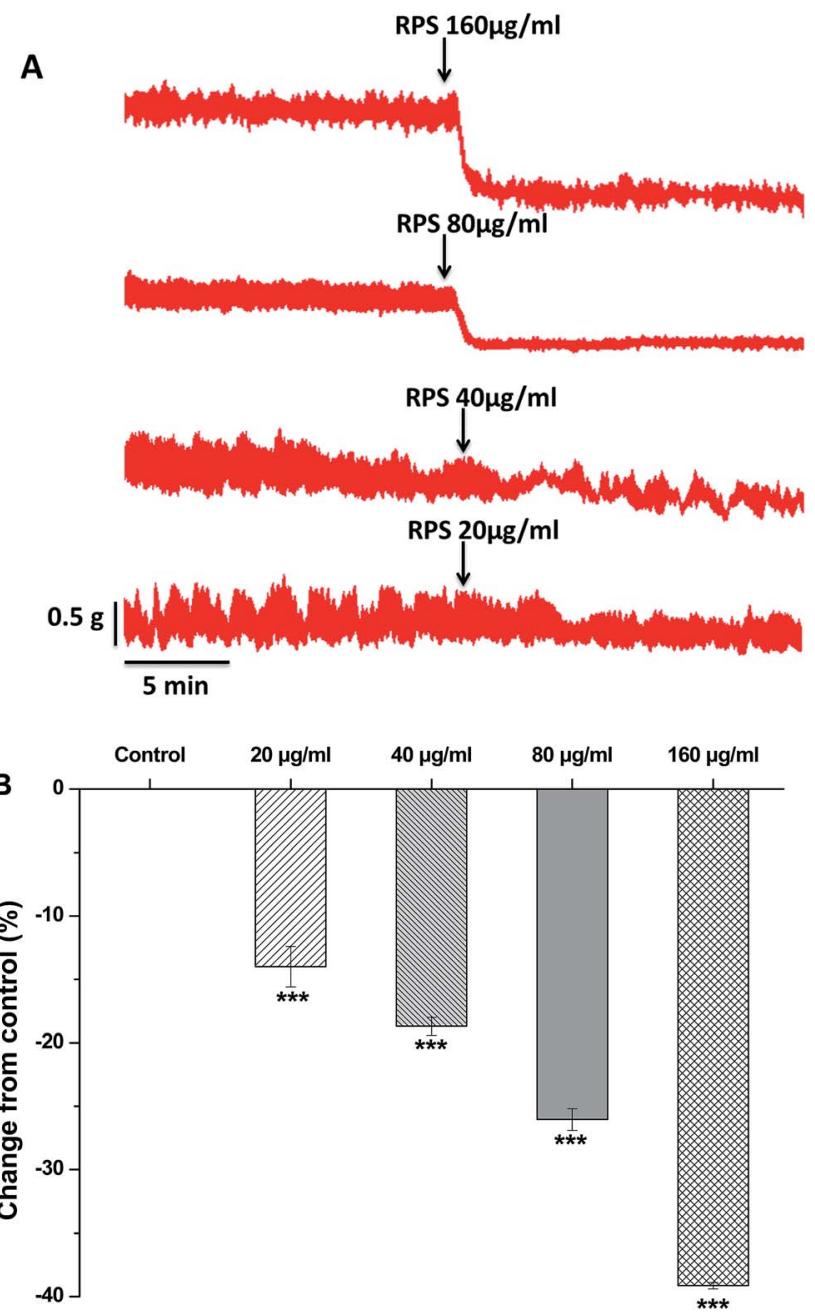

Fig. 6 Effects of RPS $\left(20-160 \mu \mathrm{g} \mathrm{m}^{-1}\right)$ on the isolated gastric antral smooth muscle. ${ }^{* * *} P<0.001$ compared to control using unpaired Student's $t$-test or one-way ANOVA. Representative recording from gastric antral smooth muscle strips induced by RPS is shown in (A). Group summary data of RPS-induced changes in the amplitude is shown in (B).

competitively antagonized by RPS and the main compounds $\left(160 \mu \mathrm{g} \mathrm{ml} \mathrm{m}^{-1}, P<0.05\right)$. Moreover, the antagonistic effects on acetylcholine of polyphyllin I and polyphyllin II were stronger than that of polyphyllin VI and $\mathrm{H}$. The data suggested that the contraction of isolated gastric antral smooth muscle elicited by acetylcholine was mainly mediated by RPS and the main compounds.

\section{Effect of atropine on RPS-induced relaxation of isolated gastric antral smooth muscle}

Atropine, an antagonist of muscarinic receptors, was used to check the involvement of muscarinic receptors in inhibitory effect on isolated gastric antral smooth muscle of RPS and its main compounds.

After pretreatment of the smooth muscle strips with atropine for 15 min, RPS, polyphyllin I, polyphyllin II, polyphyllin VI or polyphyllin $\mathrm{H}\left(20-160 \mu \mathrm{g} \mathrm{ml}^{-1}\right)$ were administrated for $5 \mathrm{~min}$.
As illustrated in Fig. 11A, RPS-induced relaxation was significantly reduced by pretreatment with atropine $(10 \mu \mathrm{M})$ in a concentration-dependent manner with the maximum value of $20.83 \pm 2.39 \%(n=6)$ at a concentration of $160 \mu \mathrm{g} \mathrm{ml})^{-1}(P<$ 0.01). The relaxation induced by polyphyllin I, polyphyllin II, polyphyllin VI and polyphyllin $\mathrm{H}\left(20-160 \mu \mathrm{g} \mathrm{ml}^{-1}\right)$ on isolated gastric antral smooth muscle were also significantly attenuated (Fig. 11B-E).

\section{Discussion}

In recent years, steroidal saponins isolated from herbs have attracted scientific attention because of their structural diversity and significant biological activities. The rhizome of Paris polyphylla Sm. var. yunnanensis, found in southwestern China, is widely used in traditional Chinese medicine for the treatment of cancer and abnormal uterine bleeding. ${ }^{2}$ Our group previously provided the first report that Rhizoma Paridis total Saponins (RPS) have an effect on inhibition of gastric emptying in vivo. ${ }^{17}$

The present results demonstrated that RPS and its main compound paris saponin (polyphyllin I, II, VI and H) exhibited inhibitory activities on gastric emptying in vivo and isolated antral smooth muscle motility in vitro. Meanwhile, from the corresponding effective concentrations, it appeared that the effectiveness of RPS in relaxing ACH-induced contraction which was firstly reported.

The organization of gastric emptying is complex and involves the coordination of motor activity in the proximal stomach, the antrum, the pylorus and duodenum, as well as passive forces generated by intragastric volume. ${ }^{21}$ Neurological and gastrointestinal hormone regulation is involved in the process. From the in vivo experiments we knew that gastric emptying was delayed under the influence of RPS alone, this delay became more prominent when the concentration of RPS was increased to $500 \mathrm{mg} \mathrm{kg}^{-1}$. Both of mosapride and neostigmine enhanced the gastric emptying. Neostigmine, an acetylcholinesterase (AChE) inhibitor and mosapride, a serotonin $5-\mathrm{HT}_{4}$ receptor agonist, have been reported to improve gastrointestinal motility in dogs or patients. ${ }^{22}$ As shown in Fig. 3, the gastric emptying improved by neostigmine and mosapride was significantly abolished by administration with RPS (500 $\left.\mathrm{mg} \mathrm{kg}^{-1}, P=0.000\right)$. Neostigmine and mosapride promoted the gastric emptying via increasing the content of acetylcholine. Thereby, we speculated that the inhibition effect of RPS on gastric emptying was related to acetylcholine.

Treatment of the animals with adrenalin, atropine and dopamine also reduced the rate of gastric emptying. Restraint stress significantly inhibited gastric emptying. Adrenalin as the $\alpha$ - and $\beta$-adrenoceptor agonist could suppress the gastric emptying. In the further study, $\alpha_{1^{-}}, \alpha_{2^{-}}, \beta_{1^{-}}$, and $\beta_{2^{-}}$-adrenoceptor antagonists did not affect this restraint stress-induced inhibition of gastric emptying, $\beta_{3}$-adrenoceptor antagonist significantly cancelled the restraint stress-induced inhibition of gastric emptying. ${ }^{23}$ The present results showed that adrenalin inhibited the gastric emptying and the inhibitory effect was significantly enhanced after pre-treatment with RPS (Fig. 4, $P=$ 

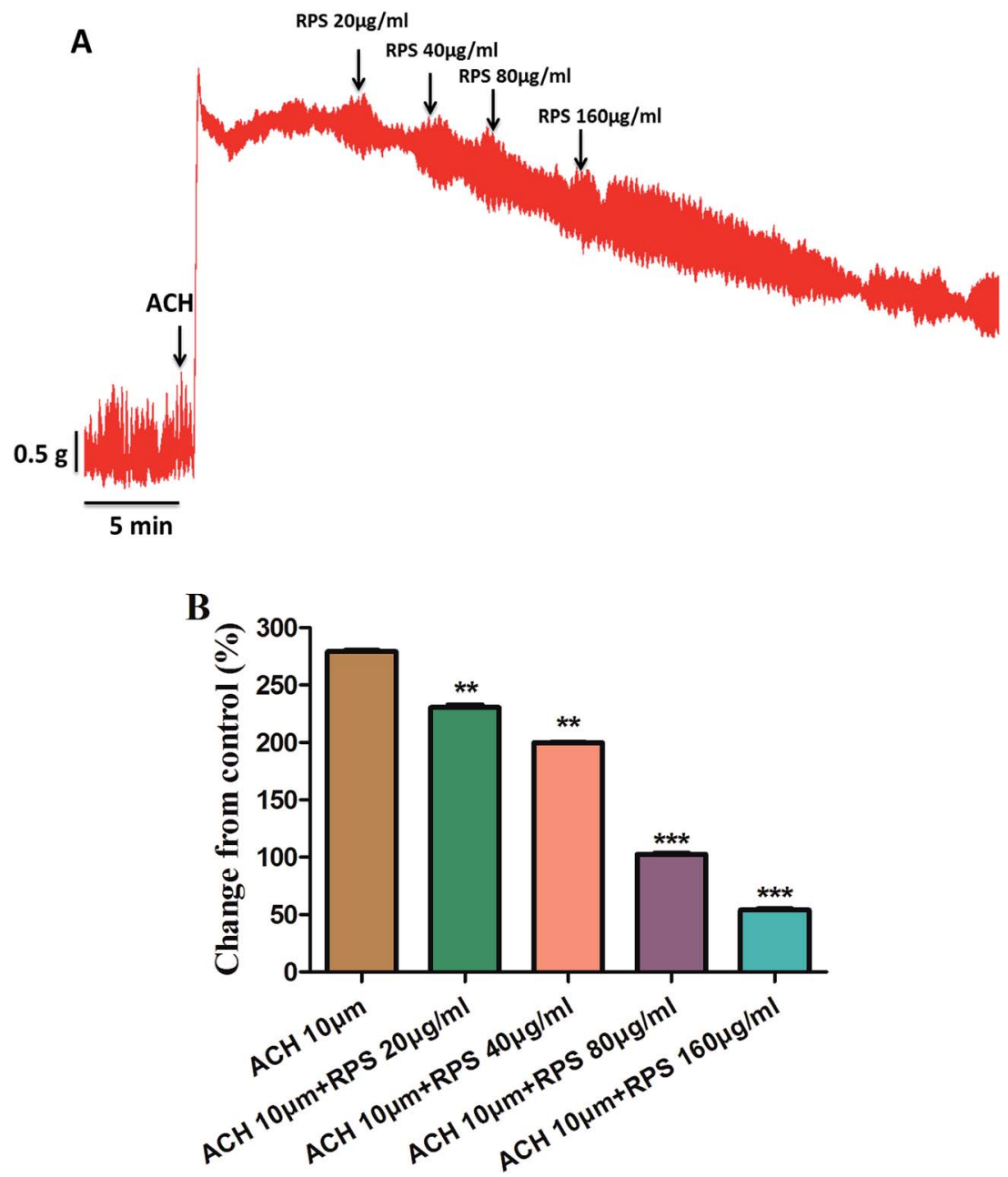

Fig. 7 Effects of RPS on $\mathrm{ACH}$-induced contraction of isolated gastric antral smooth muscle. After pretreatment of the smooth muscle strips with $\mathrm{ACH}(10 \mu \mathrm{M})$ for $10 \mathrm{~min}$, cumulative additions of RPS $\left(20-160 \mathrm{mg} \mathrm{ml}^{-1}\right)$ was treated for $5 \mathrm{~min}$, respectively. $* * P<0.01, * * * P<0.001$ compared to $\mathrm{ACH}(10 \mu \mathrm{M})$.

$0.016, P=0.000$ ), which implied that the inhibitory effect of RPS on gastric emptying had no connection with adrenoceptor.

Dopamine as a dopamine and adrenoceptor agonist regulated food intake by modulating food reward and motivation without crossing the blood-brain barrier. ${ }^{24}$ The inhibitory effect of dopamine on gastric motility is thought to be mediated via

Table 1 Inhibitory effects of RPS on isolated gastric antral circular smooth muscle ${ }^{a}$

\begin{tabular}{lll}
\hline Group & Tension $(\mathrm{g})$ & Reduction $(\%)$ \\
\hline Control & $1.34 \pm 0.05$ & \\
ACH $10 \mu \mathrm{M}$ & $5.07 \pm 0.02$ & \\
ACH $10 \mu \mathrm{M}+$ RPS $20 \mu \mathrm{g} \mathrm{ml}^{-1}$ & $4.42 \pm 0.05^{* *}$ & 12.78 \\
ACH $10 \mu \mathrm{M}+$ RPS $40 \mu \mathrm{g} \mathrm{ml}^{-1}$ & $4.00 \pm 0.02^{* * *}$ & 21.07 \\
ACH $10 \mu \mathrm{M}+$ RPS $80 \mu \mathrm{g} \mathrm{ml}^{-1}$ & $2.70 \pm 0.03^{* * *}$ & 46.64 \\
ACH $10 \mu \mathrm{M}+$ RPS $160 \mu \mathrm{g} \mathrm{ml}^{-1}$ & $2.06 \pm 0.02^{* * *}$ & 59.34
\end{tabular}

${ }^{a}$ Results as means \pm S.E.M. $(n=6) .{ }^{* *} P<0.01,{ }^{* * *} P<0.001$, significantly different when compared with the $\mathrm{ACH}(10 \mu \mathrm{M})$ group.

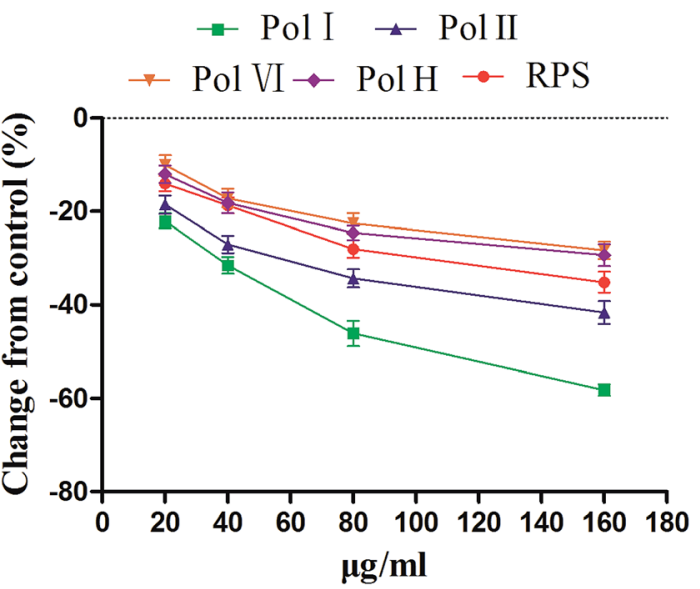

Fig. 8 Effects of RPS, polyphyllin I (Pol I), polyphyllin II (Pol II), polyphyllin VI (Pol VI) and polyphyllin $\mathrm{H}(\mathrm{Pol} \mathrm{H})\left(20-160 \mu \mathrm{g} \mathrm{ml}^{-1}\right)$ on gastric antral circular smooth muscle motility. The average amplitude were measured by isometric force transducers before $(5 \mathrm{~min})$ and after (15 $\mathrm{min}$ ) treatment of RPS. The values are represented as a percentage of the measurement before administration of RPS (\% of control, mean \pm S.E.M.). Paired or unpaired Student's $t$-test was used $(n=6)$. 
a decrease in acetylcholine release resulting from stimulation of enteric neuronal dopamine receptors. In the research, dopamine showed inhibitory effect on gastric emptying and the inhibitory effect was significantly enhanced after pre-treatment with RPS (Fig. 4A, $P=0.037$ ), but the effect was weaker than RPS alone. The results indicated that dopamine may weaken the inhibitory effect of RPS on gastric emptying. Numerous physiological and pharmacological studies have shown that dopamine has an inhibitory effect on gastric motility by a decrease in acetylcholine release resulting from the stimulation of peripheral dopamine receptors. ${ }^{25}$ However, previous studies have shown that the delay in gastric emptying that is induced by dopamine receptor agonists is mainly inhibited by centrally acting dopamine receptor antagonists. ${ }^{26}$ It can speculate that RPS may have the effect to competitive antagonism the dopamine receptor when administrated with dopamine. The mechanism of gastric emptying administrated with RPS and dopamine need further studies.
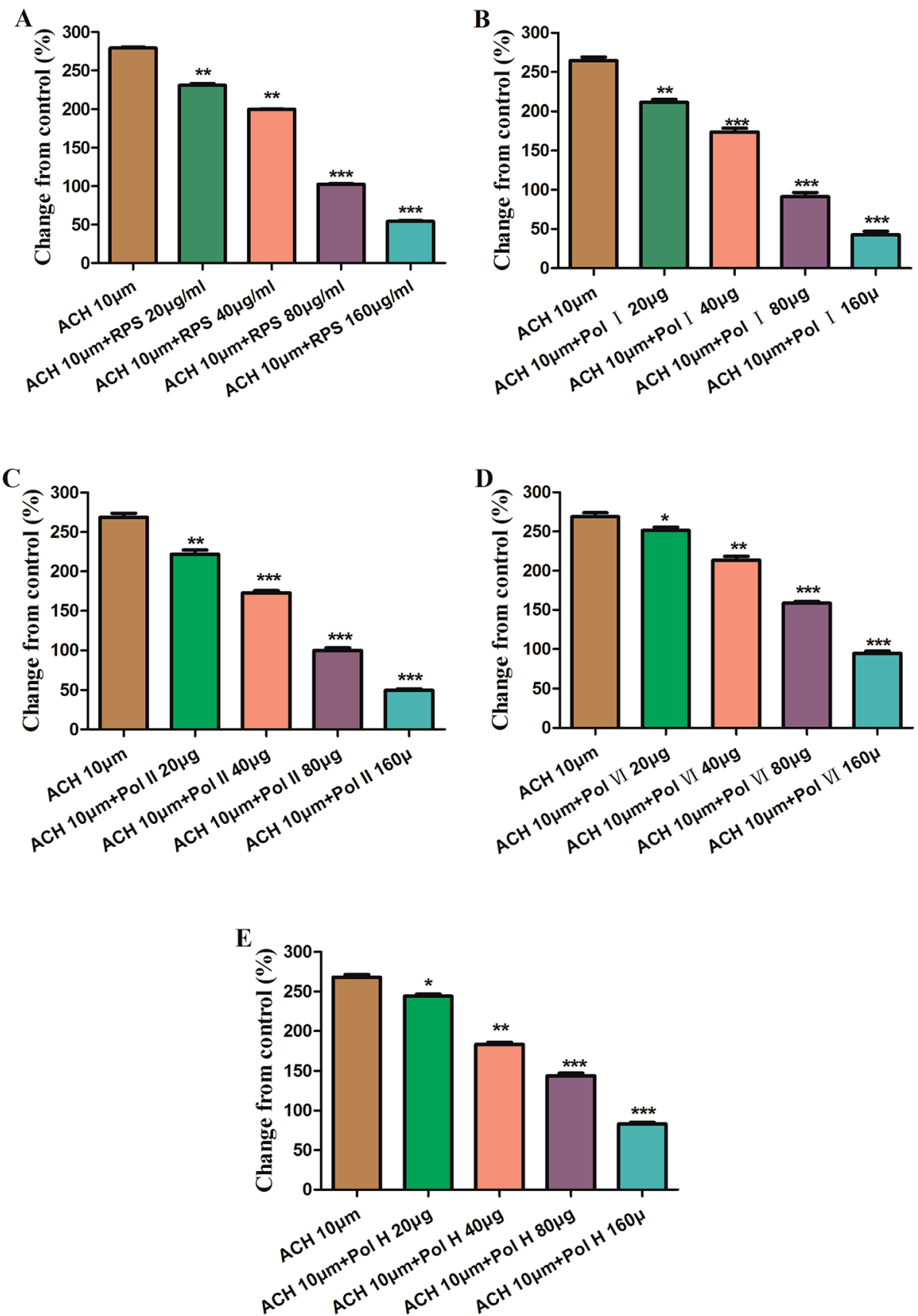

Fig. 9 Effects of RPS (A), polyphyllin I (Pol I, (B)), polyphyllin II (Pol II, (C)), polyphyllin VI (Pol VI, (D)) and polyphyllin H (Pol H, (E)) on acetylcholine $(10 \mu \mathrm{M})$ induced contraction of isolated antral smooth muscle strips. The isolated tissues were preincubated with DMSO (vehicle control), acetylcholine $(10 \mu \mathrm{M})$ for 5 min before priming with polyphyllin I, II, VI or H $\left(20-160 \mu \mathrm{gll}^{-1}\right)$. Values are expressed as mean \pm S.E.M. $(n=6)$. ${ }^{*}<<$ $0.05, * * P<0.01$ and $* * * P<0.001$ compared to $\mathrm{ACH}(10 \mu \mathrm{M})$ using two-way ANOVA with Student's $t$-test. 


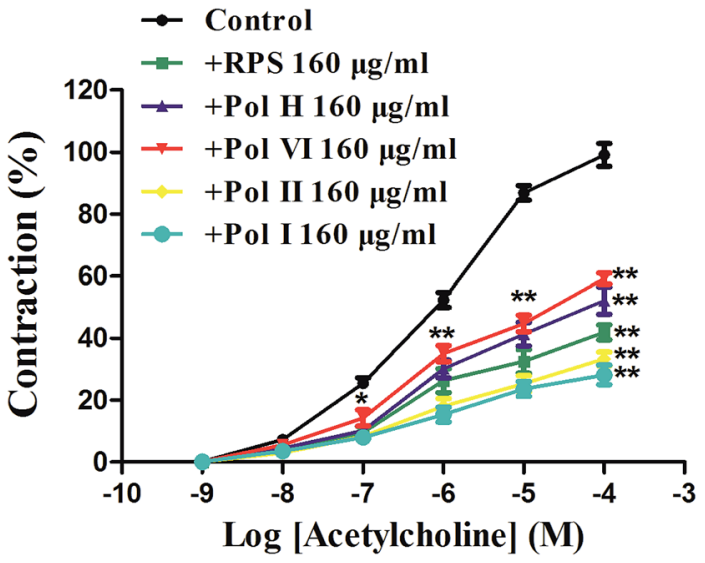

Fig. 10 Cumulative concentration-response curves for acetylcholine in the absence or presence of increasing concentrations of RPS, polyphyllin I (Pol I), polyphyllin II (Pol II), polyphyllin VI (Pol VI) and polyphyllin $\mathrm{H}(\mathrm{Pol} H)\left(160 \mu \mathrm{g} \mathrm{ml}^{-1}\right)$ on isolated gastric antral smooth muscle. ${ }^{*} P<0.05$ and $* * P<0.01$ compared to control using unpaired Student's t-test or one-way ANOVA.

Cholinergic antagonists were shown to decrease antral contractility and slow gastric emptying. The cholinergic pathway in controlling the flow of food from the stomach to the duodenum was one of the important ways. In the present study, atropine treatment induced a significant decrease of gastric emptying as the reported research. ${ }^{27}$ Administration of RPS with pretreatment by atropine had significantly effect on gastric emptying with dose dependent, but the inhibition rates were weaker than RPS alone (Fig. 4A). The attenuation of the inhibitory effect of RPS on gastric emptying under muscarinic antagonist suggested that RPS may interfere with the contractile effect of acetylcholine.

As gastric emptying has been shown to be related to smooth muscle contraction, the effect of RPS on the spontaneous contractility of rat gastric antral smooth muscle was evaluated in vitro. In the concentrations of $20 \mu \mathrm{g} \mathrm{ml}^{-1}$ to $160 \mu \mathrm{g} \mathrm{ml}{ }^{-1}$, RPS decreased the tension of antral spontaneous phasic contraction with the rate of $18.70 \pm 0.71 \%, 26.05 \pm 0.86 \%$ and $39.14 \pm$ $0.25 \%$, respectively. The effect of RPS on ACH-induced contractility of gastric antral smooth muscle was also investigated. The results demonstrated that treatment with RPS (160 $\mu \mathrm{g} \mathrm{ml}^{-1}$ ) could mostly abolish the contractile effect of ACH (10 $\mu \mathrm{M})$ on gastric antral smooth muscles, which suggested that the activity of the RPS was connected with acetylcholine receptors.

In the present research, effect of the saponins with pennogenins (polyphyllin VI, H) and saponins with diosgenins (polyphyllin I, II) on isolated antral smooth muscle was examined. Our series of experiments demonstrate that the main compounds in RPS, such as polyphyllin I, II, VI and $\mathrm{H}$ showed the significant inhibitory effect on gastric antral smooth muscle contractility, but the inhibitions of polyphyllin VI and $\mathrm{H}$ were weaker than that of polyphyllin I and II (Fig. 8). We also observed that the application of polyphyllin I, II, VI and $\mathrm{H}$ partly suppressed the effect of $\mathrm{ACH}(10 \mu \mathrm{M})$ on gastric antral smooth muscle contraction, and the suppressed effect of polyphyllin I and II was stronger as above. It is evident that the inhibitory effect of monomeric compounds in RPS (polyphyllin I, II, VI and H) is correlated with the acetylcholine receptors, especially the saponins with diosgenins. These findings suggest that the spirostanol structure is essential for the inhibitory effect on gastric antral smooth muscle contractility and the 17-hydroxyl group may weaken the inhibitory effect against $\mathrm{ACH}(10 \mu \mathrm{M})$-induced contractility.

There are reports that gastrointestinal motility is regulated by various neurotransmitters such as 5-hydroxytryptamine (5HT) ${ }^{28}$ dopamine $^{29}$ and acetylcholine. ${ }^{30}$ Acetylcholine, an acetylcholine receptor agonist, may stimulate the gastric emptying by stimulating the muscarinic acetylcholine receptor. Atropine, a selective muscarinic receptor antagonist, may inhibit the gastric emptying by antagonism the muscarinic acetylcholine receptor. In this study, RPS and the main compounds caused a concentration-dependent relaxation in isolated gastric antral smooth muscle (Fig. 8). We also found that the contraction effect induced by acetylcholine $(10 \mu \mathrm{M})$ was attenuated by RPS, polyphyllin I, polyphyllin II, polyphyllin VI and polyphyllin $\mathrm{H}$ (Fig. 7 and 9). The present study showed that $\mathrm{ACH}$-induced contraction was significantly reduced by pretreatment with RPS and the main compounds $\left(160 \mu \mathrm{g} \mathrm{ml}^{-1}\right.$, Fig. 10), which suggested that the acetylcholine receptors might be implicated in the relaxation effect of RPS, polyphyllin I, polyphyllin II, polyphyllin VI or polyphyllin $\mathrm{H}$ on isolated gastric antral smooth muscle. Moreover, incubation of isolated gastric antral smooth muscle with atropine, a selective muscarinic receptor antagonist, significantly blunted RPS and the main compounds induced relaxation (Fig. 11). Thereby we suspect that RPS, polyphyllin I, polyphyllin II, polyphyllin VI and polyphyllin $\mathrm{H}$ inhibiting as antagonist of muscarinic receptors on gastric antral smooth muscle and the muscarinic receptor inhibition is one of the mechanisms responsible for the gastric emptying properties of RPS and the main compounds.

Saponins are well known to exhibit cytotoxic, hemolytic and gastroprotective activities, which are strongly interrelated with the nature of both the aglycone and sugar side chains. ${ }^{31-33}$ Saponins with diosgenin, pennogenin and their congeners as the aglycones constitute the most abundant types of steroid saponins in PRS. Several papers reported the correlation of the activities for pennogenins and diosgenins from the structureactivity relationship studies. Meanwhile, diosgenin and pennogenin, two major constituents in RPS, were reported to have gastroprotective effect on ethanol-induced gastric lesions in rats, which was associated with the structure of saponins. ${ }^{33}$ To our best knowledge, this is the first report of RPS with the significantly inhibitory effect on gastric antral smooth muscle contractility which may be related to the muscarinic receptors. Furthermore, the main pure compounds in RPS serve as inhibitors which were relevant to structure had never reported before. 

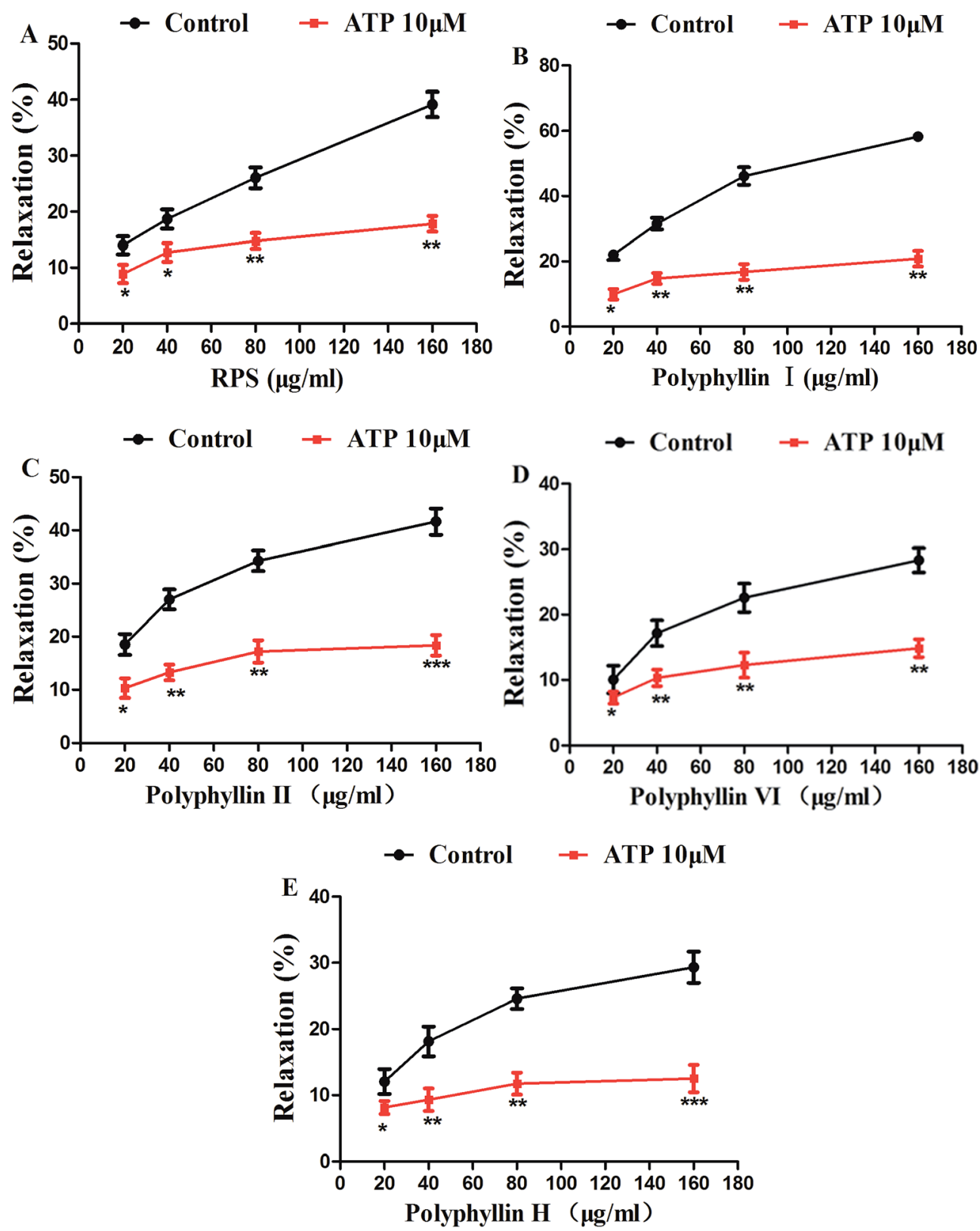

Fig. 11 Effects of RPS, polyphyllin I, polyphyllin II, polyphyllin VI and polyphyllin $\mathrm{H}\left(20-160 \mu \mathrm{g} \mathrm{ml}^{-1}\right)$ on atropine-induced relaxation of isolated gastric antral smooth muscle. After pretreatment of the smooth muscle strips with atropine for $15 \mathrm{~min}$, RPS, polyphyllin I, polyphyllin II, polyphyllin VI and polyphyllin $\mathrm{H}$ $\left(20-160 \mu \mathrm{g} \mathrm{ml}^{-1}\right)$ were treated for $5 \mathrm{~min}$. $* P<0.05, * * P 0.01$ and $* * * P<0.001$ compared to control using unpaired Student's $t$-test or one-way ANOVA.

\section{Conclusion}

In summary, our present results suggest Rhizoma Parisdis total Saponins (RPS) and its two kinds of saponins have inhibitory effect on gastric emptying and gastric antral smooth muscle contractility and the muscarinic receptors may be the major site of RPS on inhibiting gastric emptying and gastric antral smooth muscle contractility. Moreover, the 17-hydroxyl group of spirostan may influence the inhibitory effect of both gastric emptying and gastric antral smooth muscle contractility. Further studies are needed to elucidate the exact mechanisms and the structure-activity relationship of Paris polyphylla saponin that are responsible for these pharmacological observations.

\section{Conflict of interest}

We have no conflict of interest in this research.

\section{Abbreviation}

$\begin{array}{ll}\mathrm{ACH}_{5} & \text { Acetylcholine } \\ 5-\mathrm{HT}_{4} & \text { 5-Hydroxytryptamine } 4 \\ \mathrm{AD} & \text { Adrenalin hydrochloride } \\ \mathrm{AT} & \text { Atropine } \\ \mathrm{DA} & \text { Dopamine } \\ \text { GASMC } & \text { Gastric antral smooth muscle contractility }\end{array}$


MO Mosapride citrate

NE Neostigmine

RPS Rhizoma Paridis total saponins

\section{Acknowledgements}

The authors acknowledge the "Drug Creation Project 2014ZX09301307-018 and 2013ZX09103002-010 from Science and Technology in China".

\section{References}

1 M.-Y. Lee, N.-H. Lee, D. Jung, J.-A. Lee, C.-S. Seo, H. Lee, J.-H. Kim and H.-K. Shin, Int. Immunopharmacol., 2010, 10, 474-480.

2 Y. Tian, L. H. Zheng, Z. Y. Xu, L. Q. Sun, C. K. Gao, Q. Z. Zheng, Z. H. Zhang and Y. Shu, J. Tradit. Chin. Med., 1986, 6, 178-182.

3 Z. Liu, W. Gao, S. Man, J. Wang, N. Li, S. Yin, S. Wu and C. Liu, J. Ethnopharmacol., 2012, 144, 67-72.

4 Z. Liu, N. Li, W. Gao, S. Man, S. Yin and C. Liu, J. Ethnopharmacol., 2012, 142, 789-794.

5 S. Man, W. Gao, Y. Zhang, L. Huang and C. Liu, Biomed. Chromatogr., 2011, 25, 712-719.

6 S. Man, W. Gao, Y. Zhang, X. Jin, C. Ma, X. Huang and Q. Li, Anal. Bioanal. Chem., 2009, 395, 495-505.

7 S. Man, W. Gao, Y. Zhang, J. Wang, W. Zhao, L. Huang and C. Liu, J. Chromatogr. B: Anal. Technol. Biomed. Life Sci., 2010, 878, 2943-2948.

8 S. Man, W. Gao, Y. Yan, Z. Liu and C. Liu, J. Ethnopharmacol., 2011, 137, 1221-1227.

9 S. Man, W. Gao, Y. Zhang, Z. Liu, L. Yan, L. Huang and C. Liu, Cancer Biol. Ther., 2011, 11, 592-598.

10 S. Man, W. Gao, Y. Zhang, C. Ma, L. Yang and Y. Li, Arch. Pharmacal Res., 2011, 34, 43-50.

11 S. Man, W. Gao, Y. Zhang, L. Yan, C. Ma, C. Liu and L. Huang, Steroids, 2009, 74, 1051-1056.

12 E. Tachikawa, K. Kudo, K. Harada, T. Kashimoto, Y. Miyate, A. Kakizaki and E. Takahashi, Eur. J. Pharmacol., 1999, 369, 23-32.

13 Z. Qu, J. Z. Zhang, W. Y. Gao, H. M. Guo and C. X. Liu, J. Ethnopharmacol., 2014, 155, 203-212.

14 Y. Y. Shi, Y. Zhang, F. Y. Zhao, H. Ruan, H. H. Huang, L. F. Luo and L. Li, Sci. Rep., 2014, 4, 1-12.
15 M. D. Gershon and J. Tack, Gastroenterology, 2007, 132, 397414.

16 G. Tobin, D. Giglio and O. Lundgren, J. Physiol. Pharmacol., 2009, 60, 3-21.

17 Z. Liu, W. Gao, S. Man, Y. Zhang, H. Li, S. Wu, J. Zhang and C. Liu, Environ. Toxicol. Pharmacol., 2014, 38, 31-40.

18 Z. Liu, W. Gao, S. Man, J. Wang, N. Li, S. Yin, S. Wu and C. Liu, J. Ethnopharmacol., 2012, 144, 67-72.

19 J. Yin, J. Song, Y. Lei, X. Xu and J. D. Chen, Am. J. Physiol.: Gastrointest. Liver Physiol., 2014, 306(9), 796-801.

20 W. Huang, X. Huang, Z. Xing, X. Qiu, Y. Wang, R. Fan, W. Liu, P. Ren, Z. Liu and H. Zhou, J. Gastrointest. Surg., 2011, 15, 87-96.

21 T. H. Moran, J. B. Wirth, G. J. Schwartz and P. R. McHugh, Am. J. Physiol., 1999, 276, R997-R1002.

22 M. Kawachi, Y. Matsunaga, T. Tanaka, Y. Hori, K. Ito, K. Nagahama, T. Ozaki, N. Inoue, R. Toda, K. Yoshii, M. Hirayama, Y. Kawabata and M. Takei, Eur. J. Pharmacol., 2011, 666, 218-225.

23 F. Tsukada, Y. Nagura, S. Abe, N. Sato and Y. Ohkubo, Biol. Pharm. Bull., 2003, 26, 368-370.

24 W. J. Huang and E. J. Chien, Chin. J. Physiol., 2012, 55, 259266.

25 Y. Nagahata, T. Urakawa, H. Kuroda, K. Tomonaga, H. Idei, N. Kawakita, K. Yoshizumi and Y. Saitoh, Gastroenterol. Jpn., 1992, 27, 482-487.

26 B. Costall, S. J. Gunning, R. J. Naylor and K. H. Simpson, Eur. J. Pharmacol., 1983, 91, 197.

27 S. Amira, S. Soufane and K. Gharzouli, Exp. Toxicol. Pathol., 2005, 57, 59-64.

28 Y. Mine, T. Yoshikawa, S. Oku, R. Nagai, N. Yoshida and K. Hosoki, J. Pharmacol. Exp. Ther., 1997, 283, 1000-1008.

29 Z. S. Li, C. Schmauss, A. Cuenca, E. Ratcliffe and M. D. Gershon, J. Neurosci., 2006, 26, 2798-2807.

30 W. Fujii, H. Hori, Y. Yokoo, Y. Suwa, H. Nukaya and K. Taniyama, Alcohol.: Clin. Exp. Res., 2002, 26, 677-681.

31 M. Takechi and Y. Tanaka, Planta Med., 1995, 61, 76-77.

32 Y. Cong, X. Liu, L. Kang, Z. Yu, Z. Zhao, J. Li, B. Ma and Y. Cong, Thromb. Res., 2012, 129, E209-E216.

33 H. Matsuda, Y. Pongpiriyadacha, T. Morikawa, A. Kishi, S. Kataoka and M. Yoshikawa, Bioorg. Med. Chem. Lett., 2003, 13, 1101-1106. 